\title{
Analysis of the gene coding for steroidogenic factor 1 (SF1, NR5A1) in a cohort of 50 Egyptian patients with $46, X Y$ disorders of sex development
}

\author{
Sally Tantawy 1,2, Inas Mazen², Hala Soliman ${ }^{3}$, Ghada Anwar ${ }^{4}$, Abeer Atef ${ }^{4}$, \\ Mona El-Gammal ${ }^{2}$, Ahmed El-Kotoury ${ }^{2}$, Mona Mekkawy5 ${ }^{5}$, Ahmad Torky², \\ Agnes Rudolf', Pamela Schrumpf ${ }^{1}$, Annette Grüters ${ }^{1}$, Heiko Krude', \\ Marie-Charlotte Dumargne, ${ }^{6}$ Rebekka Astudillo', Anu Bashamboo', \\ Heike Biebermann ${ }^{1}$ and Birgit Köhler ${ }^{1}$
}

'Institute of Experimental Paediatric Endocrinology, University Children's Hospital, Charité, Humboldt University, Berlin, Germany, ${ }^{2}$ Department of Clinical Genetics and ${ }^{3}$ Department of Medical Molecular Genetics, Division of Human Genetics and Genome Research, National Research Centre, Cairo, Egypt, ${ }^{4}$ Department of Paediatrics, Cairo University, Cairo, Egypt, ${ }^{5}$ Department of Cytogenetics, Division of Human Genetics and Genome Research, National Research Centre, Cairo, Egypt and ${ }^{6}$ Human Developmental Genetics, Institut Pasteur, Paris, France

Correspondence should be addressed to S Tantawy

Email

sallytantawy@live.com

\begin{abstract}
Objective: Steroidogenic factor 1 (SF1, NR5A1) is a key transcriptional regulator of genes involved in the hypothalamicpituitary-gonadal axis. Recently, SF1 mutations were found to be a frequent cause of $46, X Y$ disorders of sex development (DSD) in humans. We investigate the frequency of NR5A1 mutations in an Egyptian cohort of XY DSD.

Design: Clinical assessment, endocrine evaluation and genetic analysis of 50 Egyptian XY DSD patients (without adrenal insufficiency) with a wide phenotypic spectrum.

Methods: Molecular analysis of NR5A1 gene by direct sequencing followed by in vitro functional analysis of the two novel missense mutations detected.

Results: Three novel heterozygous mutations of the coding region in patients with hypospadias were detected. p.Glu121AlafsX25 results in severely truncated protein, p.Arg62Cys lies in DNA-binding zinc finger, whereas p.Ala154Thr lies in the hinge region of SF1 protein. Transactivation assays using reporter constructs carrying promoters of anti-Müllerian hormone (AMH), CYP11A1 and TESCO core enhancer of Sox9 showed that p.Ala154Thr and p.Arg62Cys mutations result in aberrant biological activity of NR5A1. A total of 17 patients (34\%) harboured the p.Gly146Ala polymorphism.

Conclusion: We identified two novel NR5A1 mutations showing impaired function in 23 Egyptian XY DSD patients with hypospadias (8.5\%). This is the first study searching for NR5A1 mutations in oriental patients from the Middle East and Arab region with XY DSD and no adrenal insufficiency, revealing a frequency similar to that in European patients (6.5-15\%). We recommend screening of NR5A1 in patients with hypospadias and gonadal dysgenesis. Yearly follow-ups of gonadal function and early cryoconservation of sperms should be performed in XY DSD patients with NR5A1 mutations given the risk of future fertility problems due to early gonadal failure.
\end{abstract}

(ㄷ) 2014 European Society of Endocrinology Printed in Great Britain
European Journal of

Endocrinology

(2014) 170, 759-767 


\section{Introduction}

Disorders of sex development (DSDs) are complex disorders with atypical chromosomal, gonadal or anatomical sex (1). DSDs are classified into three groups: i) DSD with numerical sex chromosomal aberrations, ii) XY DSD and iii) XX DSD. Sex chromosome DSD consists mainly of disorders with gonadal dysgenesis due to sex chromosome imbalances such as Turner syndrome (45,X and mosaicism), Klinefelter syndrome (47,XXY), mixed gonadal dysgenesis $(45, \mathrm{X} 0 / 46, \mathrm{XY})$ and chimeric DSD $(46, \mathrm{XX} / 46, \mathrm{XY})$. XY DSD comprises mainly testicular dysgenesis, defects of androgen synthesis or action and hypospadias. XX DSD includes congenital adrenal hyperplasia, ovarian dysgenesis and uterine/vaginal malformations (1). In Egypt, the occurrence of DSD is rare with an incidence of $1: 5000$ (2) similar to $1: 4500$ worldwide (3). In Egypt, 46,XY DSD constitutes the majority of DSD cases (65.9\%) (4) with androgen insensitivity syndrome and 5 - $\alpha$-reductase deficiency being the two most frequent 46 , XY DSD aetiologies due to high consanguinity. They constitute $64 \%$ among all reported cases (5). However, in many cases the pathogenetic cause is unknown.

During the last 10 years, steroidogenic factor 1 (SF1, NR5A1) has been found to play a pivotal role in human sex differentiation. SF1 is a key transcriptional regulator of many genes involved in the hypothalamic-pituitarygonadal axis and adrenal cortex (6). Sf1 null mice demonstrate complete gonadal dysgenesis and adrenal failure (7). However, humans harbouring heterozygous NR5A1 mutations display a milder phenotype. The majority of cases display 46,XY DSD with ambiguous genitalia or hypospadias due to partial gonadal dysgenesis but no adrenal insufficiency. To date, about 60 different NR5A1 mutations have been reported in humans with DSDs. So far, there is no apparent genotype-phenotype correlation in patients with NR5A1 mutations. The phenotypic spectrum has been extended, involving not only ambiguous genitalia and hypospadias due to gonadal dysgenesis $(8,9,10)$, but also vanishing testis syndrome (11), isolated hypoplastic penis (12) and male infertility $(13,14)$. Moreover, NR5A1 mutations were also found in 46,XX females with premature ovarian failure and primary ovarian insufficiency $(15,16,17,18,19)$. Altogether, NR5A1 mutations have emerged as being the most frequent cause (6.5-15\%) of different phenotypes of $46, \mathrm{XY}$ DSD in Western countries. Our aim is to investigate whether NR5A1 mutations are also a cause of 46,XY DSD in Egypt.

\section{Subjects and methods}

\section{Cohort}

A cohort of 50 Egyptian 46,XY DSD patients were recruited from the Pediatric Endocrinology Clinic of Cairo University and the Clinical Genetics and Endocrinology Departments of National Research Centre (NRC) in Cairo, Egypt. Patients' chronological ages ranged from 2 months to 33 years at first presentation. The phenotypic spectrum included complete female external genitalia with/without uterus $(n=8)$, ambiguous genitalia without uterus $(n=5)$, vanishing/atrophic testes $(n=10)$, hypospadias with normally descended testis $(n=9)$, hypospadias with at least one undescended testis $(n=14)$ and isolated hypoplastic phallus $(n=4)$. Patients with syndromic forms of gonadal dysgenesis or chromosomal abnormalities were excluded. Among the 50 patients, 39 were reared as males, 11 as females and one was reared as female at birth then her sex was changed to male at 2 years of age. Written informed consent for genetic analysis was obtained according to institutional ethical guidelines from the patients and/or their parents.

Work-up included cytogenetic analysis by G-banding technique in 50 metaphases (20), and pelviabdominal ultrasound. Testosterone, precursors and dihydrotestosterone (DHT) were measured before and after human chorionic gonadotropin (hCG) stimulation. In some cases, pelvic laparoscopy, biopsy and histological analysis of the gonads were performed.

\section{Molecular analysis of NR5A1 gene}

Molecular analysis of exons $2-7$ of the gene encoding SF1 (NR5A1) was performed as described previously (21). Numbering of the mutations is based on GenBank reference DNA sequence NM_004959.4, with the A of the ATG initiation codon designated +1 (www.hgvs.org/mutnomen).

A total of 100 Egyptian controls (200 alleles) were sequenced for both the mutations and the singlenucleotide polymorphisms (SNPs).

\section{Functional analysis}

Vector containing full-length mouse Nr5a1, pCNA3NR5A1-myc and the mouse TESCO reporter were a gift from Dr Francis Poulat, Institut de Génétique Moléculaire de Montpellier. The reporters containing the minimal anti-Müllerian hormone (AMH) and CYP11A1 promoters $(-269)$ are described previously (17). 
A

Human

Chimp

Rhesus

Mouse

Xenopus

Elegans

Drosophila
Mutated

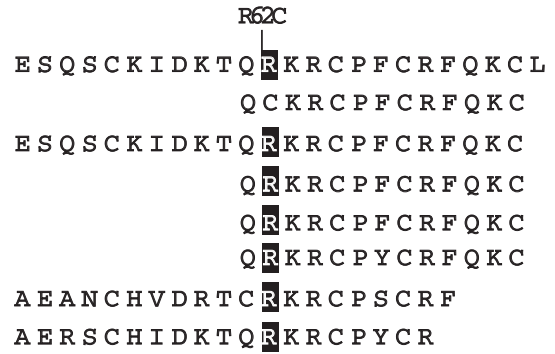

B

Human

Mutated

Chimp

Rhesus

Mouse

Xenopus
Drosophil

\begin{abstract}
A154T
SLHGPEP KGLA A P PAGPL

SLHGPEP KGLATGP PAGPL

SLHAPEP KGLAAGP PAGPL

SLHAPEP KGLAAGP PTGPL

SLHAPEP KALVSGP PSGPL

N I T PVT KN

EIQIPQV SSLTQSP DSSP
\end{abstract}

\section{Figure 1}

(A) The mutated arginine residue in position 62 is highly conserved in homologues of SF1 from all species studied to date. (B) The mutated alanine position 154 is conserved in human, chimp and rhesus but not in other species.

The NR5A1 expression vectors containing the p.Ala154Thr, p.Arg62Cys and p.Gly35Glu variants were generated by site-directed mutagenesis (QuikChange, Stratagene) of pCNA3-NR5A1-myc plasmid. The entire coding sequence of all mutant plasmids was confirmed by direct sequencing prior to functional studies. Transient gene expression assays to assess NR5A1 function were performed in 96-well plates (TPP) using human embryonic kidney cells (HEK293-T), FuGENE6 and a Dual-Luciferase Reporter Assay System (Promega) with pCMV-RL Renilla luciferase (Promega) expression as a marker of transfection efficiency. pCNA3-NR5A1-myc WT or mutant expression vector were co-transfected into HEK293-T cells with reporter and pCMV-RL. Cells were lysed $48 \mathrm{~h}$ later and luciferase assays were performed (Dual-Luciferase Reporter Assay system, Promega) using Centrox3 LB960 (Berthold Technologies). All data were standardised for Renilla activity. Results are shown as the mean \pm s.E.M. of two to three independent experiments, each performed in 12 replicates. The data were analysed statistically using Student's $t$-test. A $P$ value $<0.05$ was considered statistically significant.

\section{Results}

NR5A1 analysis revealed three novel heterozygous mutations of the coding region in three patients with hypospadias: heterozygous p.Arg62Cys (c.184 C>T), heterozygous p.Glu121AlafsX25 (c.361delGAGACAGG) and heterozygous p.Ala154Thr (c.460 G>A) (Figs 1 and 2). No NR5A1 mutations were found in patients with other phenotypes such as complete gonadal dysgenesis, isolated micropenis or vanishing/atrophic testes.

The consanguinity rate among parents of all included 46 , XY DSD patients in our study was 53\%, where $34 \%$ were first cousins and 19\% were second cousins or further relatives. In Egypt, the rate of total consanguineous marriages was 29.7\% in 2008 (22) and reached 35.3\% in 2011 (23).

\section{Case histories}

Patient 1 (p.Arg62Cys) $>$ Patient 1 is a 1 six and a halfyear-old male, born to non-consanguineous parents, presenting with severely hypoplastic phallus (stretched penile length was $1 \mathrm{~cm},<-2.5$ SDS), penile hypospadias, hypoplastic scrotum and impalpable gonads. Pelviabdominal ultrasound revealed two small testes, each 8-9 $\mathrm{mm}$ in diameter, in medial ends of respective inguinal canals and no Müllerian structures. The patient was operated upon for orchidopexy, correction of hypospadias and circumcision. During mini puberty, basal testosterone level was low normal for age, while testosterone peak after hCG stimulation (5000 IU $/ \mathrm{m}^{2}$ divided over 3 days) was markedly low. Luteinising hormone-releasing hormone (LHRH) stimulation test showed slightly elevated FSH after stimulation. AMH and inhibin B were both diminished (Table 1). The patient showed no clinical signs or symptoms of adrenal affection and had normal cortisol and DHEAS levels. Mutational analysis revealed a heterozygous p.Arg62Cys (c.184 C>T) mutation which lies in the DNA-binding zinc finger region in exon 3 and

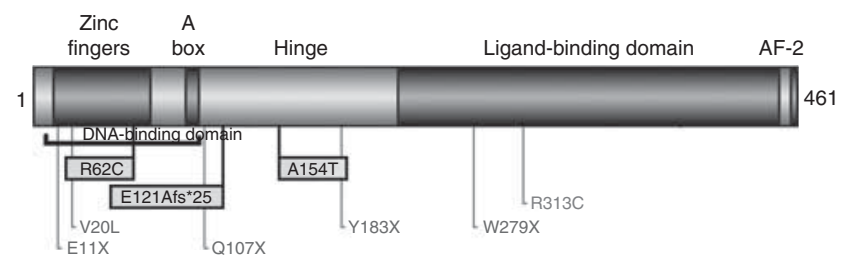

\section{Figure 2}

Cartoon structure of SF1 protein showing the location of three mutations in our study (boxed) and previously reported NR5A1 mutations in patients with hypospadias (grey) (E11X and Q107X, Kohler et al. (8); Y183X and W279X, Warman et al. (9); R313C, Allali et al. (10); V2OL and Camats et al. (16)). 


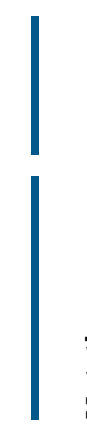

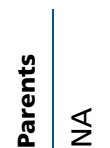
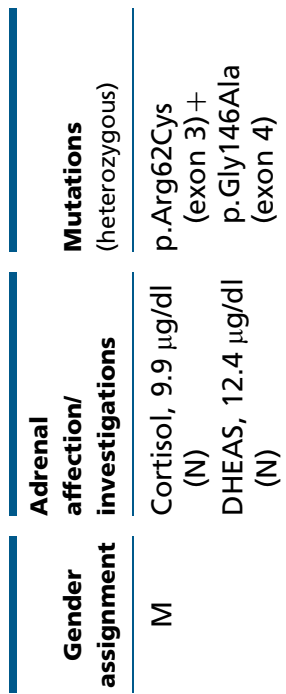

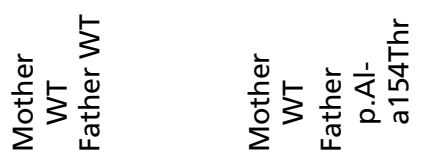

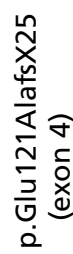

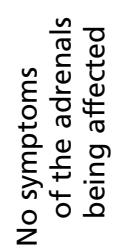

$\Sigma$
$\Sigma$

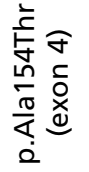

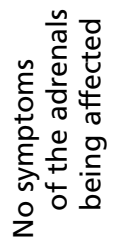

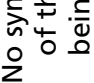

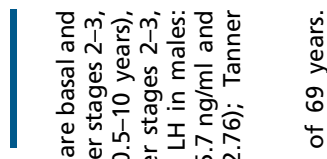

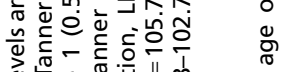

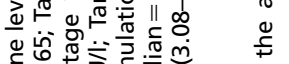

o

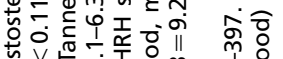

屯ै $\vee$

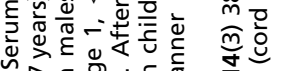

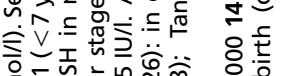

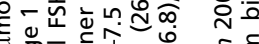

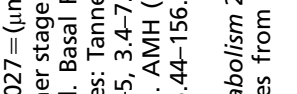

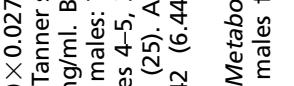

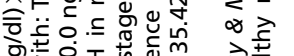

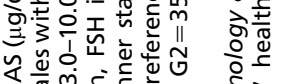

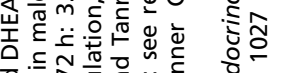

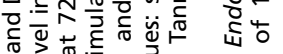

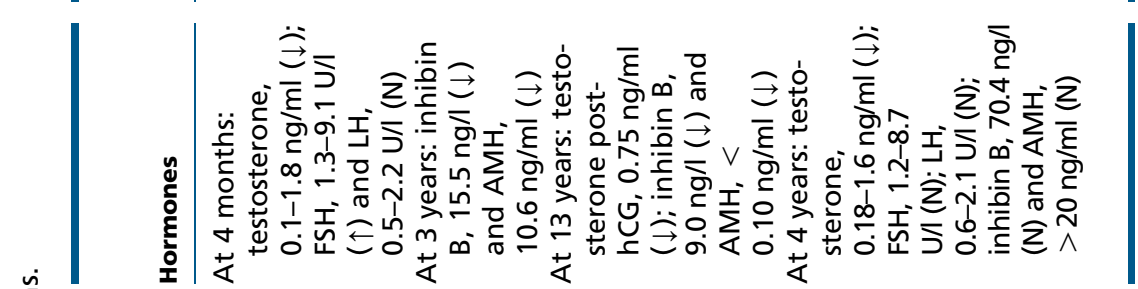

点

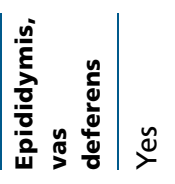

苞|

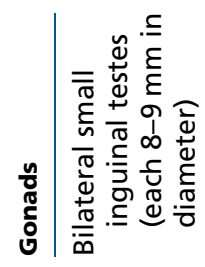

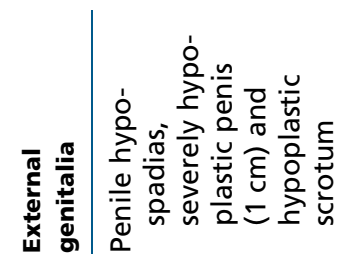

๖ั

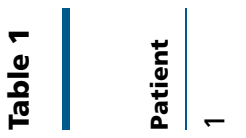

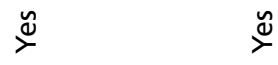

요

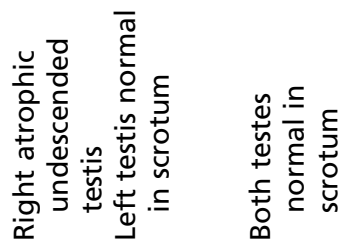

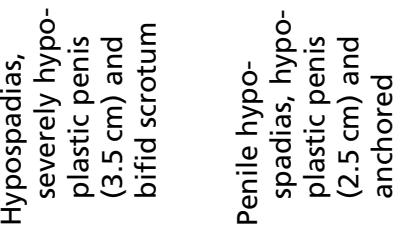

m $\quad$

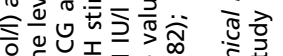

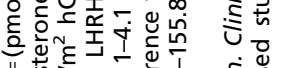

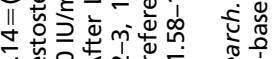

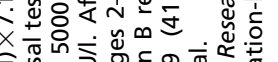

हิ

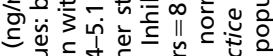

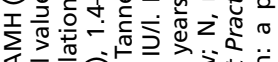

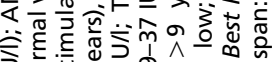

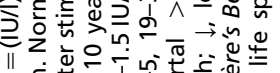

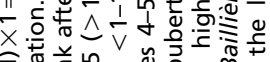

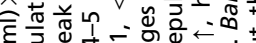

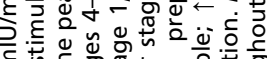

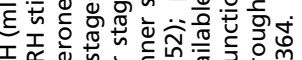

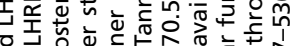

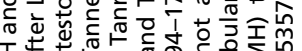

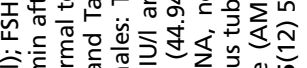

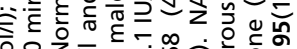

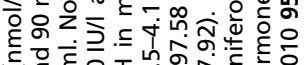

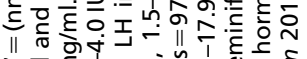

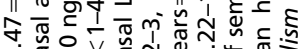

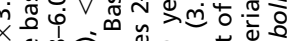

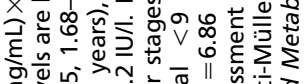

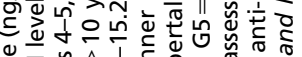

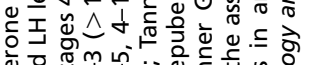

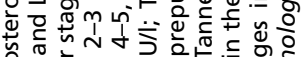

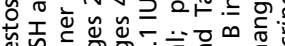

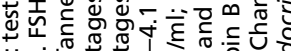

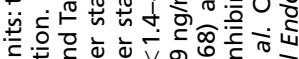

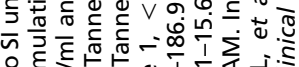

. है

c

ज्र

等 
is predicted to result in conformational change of the protein. The arginine residue in position 62 is highly conserved in all species (Fig. 1). DNA of the parents was not available for genetic analysis.

Patient 2 (p.Glu121AlafsX25) - Patient 2 is a male born to non-consanguineous parents. He presented at 13 years of age with severely hypoplastic phallus (stretched penile length was $3.5 \mathrm{~cm},<-2.5$ SDS) and impalpable right testis. The left testis was descended and of average size. Pelvic laparoscopy revealed atrophic right testis and no Müllerian structures. He was operated upon for correction of hypospadias and bifid scrotum. Serum post-hCG testosterone level was low for age. AMH and inhibin B levels were very low for age and Tanner stage (Table 1). Penile length increased to $5.5 \mathrm{~cm}$ on testosterone enanthate injections. The patient showed no signs or symptoms of the adrenals being affected. Mutational analysis revealed a heterozygous p.Glu121AlafsX25 (c.361delGAGACAGG) which is an 8 bp deletion mutation causing frameshift resulting in a premature stop codon in exon 4 (Fig. 1), predicted to produce either a severely truncated protein or no protein at all through nonsensemediated mRNA decay. It is a de novo mutation as none of the parents harbour it.

Patient 3 (p.Ala154Thr) $~$ Patient 3 is a male patient, born to consanguineous parents, who presented at 4 years of age with hypoplastic anchored phallus (stretched penile length was $2.5 \mathrm{~cm},<-2.5$ SDS) and penile hypospadias. Both testes were descended and normal. Hypospadias was surgically corrected. Serum basal testosterone level was normal for age, while post-hCG testosterone level was slightly decreased. LHRH stimulation test revealed slightly elevated FSH level. Inhibin B and AMH levels were normal (Table 1). The patient showed no clinical signs or symptoms of the adrenals being affected. Mutational analysis revealed a heterozygous p.Ala154Thr (c.460 G>A) mutation which lies in hinge region in exon 4 . The hinge region is important for transcriptional capacity of SF1 as it contains a phosphorylation site and a synergy control motif with sumoylation sites and hence is predicted to reduce the transcriptional capacity of the protein (24). Both the nucleotide and the amino acid in this position are conserved in human, chimp and rhesus but not in other species (Fig. 1). There were no SNPs found in the altered region as well as no abrogation of potential splice sites.

The heterozygous p.Ala154Thr mutation was inherited from the unaffected father. He had normal male genitalia (G5, P5, testes $25 \mathrm{ml}$ ) and a history of normal sexual activity and fathered two other children. The mother showed a normal WT sequence. All 100 Egyptian controls did not harbour this mutation.

\section{Single-nucleotide polymorphisms}

Six different SNPs were detected in our patients in both heterozygous and homozygous forms: p.Gly146Ala, p.Pro125Pro, IVS4-13, c.871-20bp C > T, p.Leu451Leu and c. ${ }^{*} 82 \mathrm{C}>$ T. The p.Gly146Ala (c.437G $>$ C, rs1110061) polymorphism, was found in 17 patients (34\%) and 31 controls in this study. We report a frequency of p.Gly146Ala in Egypt (31\%), which is synonymous with the global minor allele frequency $(27.2 \%)$ in the 1000 Genome phase 1 population (http://www.1000genomes. org) from 1094 worldwide individuals, making it a common polymorphism in Egypt as well (27). We detected the heterozygous form of this SNP (Ala/Gly genotype) in $34 \%$ of our patients (17/50) and $26 \%$ of controls (26/100). Moreover, the homozygous form (Ala/Ala genotype) was found in $5 \%$ of controls (5/100) and in none of our patients. In previous studies, the SNP p.Gly146Ala was described as having slightly reduced transcriptional activity and to be more common in cryptorchidism $(28,29)$.

Furthermore, two novel heterozygous intron 6 mutations (c. $1137+105 b \mathrm{C}>\mathrm{T}$ and c. $1137+129 \mathrm{~b} \mathrm{C}>\mathrm{A}$ ) were detected 105 and $129 \mathrm{bp}$, respectively, following exon 6. Neither of them was reported in the SNP databases (Ensembl, Exome Variant Server). Neither were detected in the control cohort.

\section{Functional analysis}

Both p.Ala154Thr and p.Arg62Cys show an aberrant transactivation of the known SF1-responsive reporters (human $A M H$ promoter, human CYP11A1 promoter and mouse TESCO core enhancer of Sox9) in human embryonic kidney, HEK293-T, cells (Fig. 3). A previously published loss of function p.Gly35Glu mutation was used as a control. The p.Arg62Cys mutant protein shows a significant reduction, whereas p.Ala154Thr shows a significant increase in its ability to stimulate either of the reporter genes' activity. The activities of the mutant proteins were calculated relative to that of the WT NR5A1, which was designated as $100 \%$.

\section{Discussion}

A growing number of heterozygous mutations in NR5A1 have been identified in patients displaying the most 

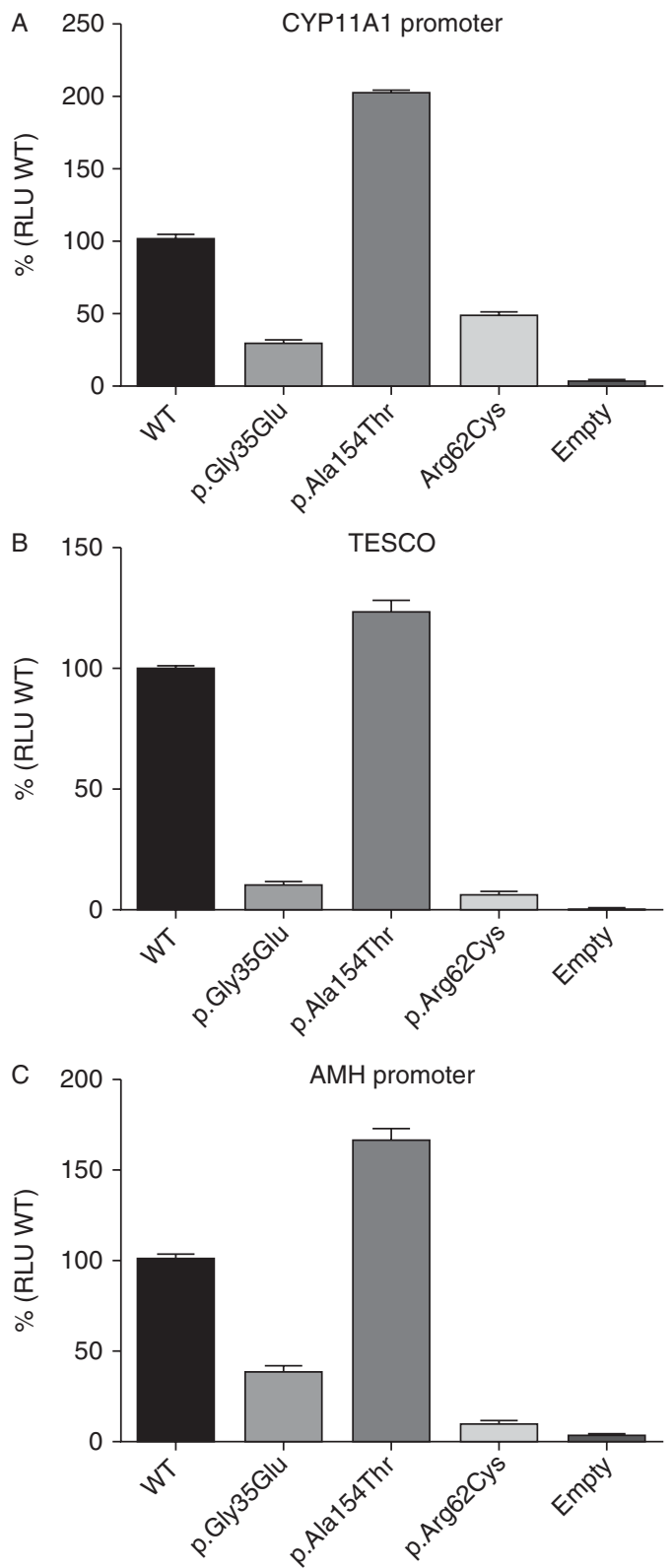

\section{Figure 3}

Effect of the SF1 mutants (p.Ala154Thr and p.Arg62Cys) on transcriptional activities of the CYP11A1 promoter (A), TESCO (B) and the $A M H$ promoter (C). Studies of transcriptional activities of p.Ala154Thr and p.Arg62Cys on the CYP11A1 promoter, TESCO and the $A M H$ promoter were performed in HEK293-T cells. The known inactivating p.Gly35Glu mutation was used as control. To compare independent experiments, the activity of the mutants is shown as the percentage of the SF1 WT activity, which is set at 100\%. Data represent the mean of two to three independent experiments, each performed in 12 replicates. The testosterone bars represent the S.E.M. Significant outliners $(\alpha=0.05)$ of the raw data have been eliminated using GraphPad Software (graphpad.com/quickcalcs/Grubbs1.cfm). common SF1 phenotype of 46,XY DSD with ambiguous genitalia due to severe partial gonadal dysgenesis at birth $(9,16,21,28,29,30,31,32,33,34,35)$. Recent studies have reported several cases with NR5A1 mutations and the milder 46,XY DSD phenotype of hypospadias $(8,9,10,16)$ (Fig. 2). We report three novel NR5A1 mutations with variable degrees of hypospadias from an Egyptian cohort of patients with 46,XY DSD. An estimated frequency of $3-5 \%$ has been reported in patients with hypospadias in Europe $(8,10)$. We found two novel NR5A1 mutations with reduced transcriptional function in 23 patients with hypospadias $(8.5 \%)$. This rather high frequency might be due to preselection of more severe cases (Fig. 2).

In 46,XY DSD patients with severe underandrogenisation (female or severely ambiguous external genitalia and cryptorchidism with or without uterus), a frequency of NR5A1 mutations of $8-15 \%(8,10,16)$ has been reported in Europe. In this study, we investigated 13 patients with a similar phenotype and could not detect any NR5A1 mutations.

All three patients with NR5A1 mutations were presenting with penile hypospadias and hypoplastic phallus. Patients 1 and 2 (p.Arg62Cys and p.Glu121AlafsX25) also displayed maldescended testes and partial gonadal dysgenesis with impaired Leydig cell and Sertoli cell functions (low testosterone, low inhibin B and $\mathrm{AMH}$ ). Patient 3 (p.Ala154Thr) showed normally descended testes, only mildly impaired Leydig cell and normal Sertoli cell function (slightly decreased testosterone, normal inhibin $\mathrm{B}$ and $\mathrm{AMH}$ ) (Table 1).

The results of the functional in vitro assays of the mutations of patients 1 and 3 were in accordance with their phenotypes. The p.Arg62Cys mutation of patient 1 showed significantly reduced transcriptional activity of the CYP11A1 and $A M H$ promoters and TESCO, while the p.Ala154Thr mutation of patient 3 did not result in reduction of transcriptional activity of any of the three reporters (Fig. 3).

Our patients demonstrated moderate clinical underandrogenisation at birth showing that Leydig cell function was already disturbed during prenatal life. In contrast, embryonic Sertoli cell function seemed to have been sufficient for adequate $\mathrm{AMH}$ production and subsequent Müllerian duct regression prenatally. In patients 1 and 2, $\mathrm{AMH}$ and inhibin B levels were diminished at 3 and 13 years of age respectively, revealing progressive Sertoli cell hypofunction as described previously in 46,XY patients with NR5A1 mutations and progressive deterioration of the Sertoli cell function with age $(13,36)$. Patient 3 displayed normal Sertoli cell function at 4 years of age. 
To date, two other mutations were reported with isolated hypospadias and normal testes $(9,10)$. Warman et al. reported a family with six members harbouring a heterozygous NR5A1 hinge region mutation (p.Tyr183X) and displaying a wide range of different phenotypes. Three affected members had isolated hypospadias, two of whom were severe perineal and one was mild glandular (9). Another case of isolated distal hypospadias carrying a de novo heterozygous missense mutation (p.Arg313Cys) located at the end of the ligand-binding domain of the NR5A1 gene was reported by Allali et al. (10) (Table 2).

So far, no clear genotype-phenotype correlation could be detected in patients with NR5A1 mutations. However, in patients with severe forms of $46, \mathrm{XY}$ DSD, previously described mutations are mostly missense mutations in the DNA-binding region (including its accessory DNA-binding domain) or in the ligand-binding domain as well as nonsense mutations leading to severe changes of the protein $(8,10,16,21,30,31,32,33,36,37,38,39)$.

Table 2 SF1 mutations described previously in the hinge region and their phenotype.

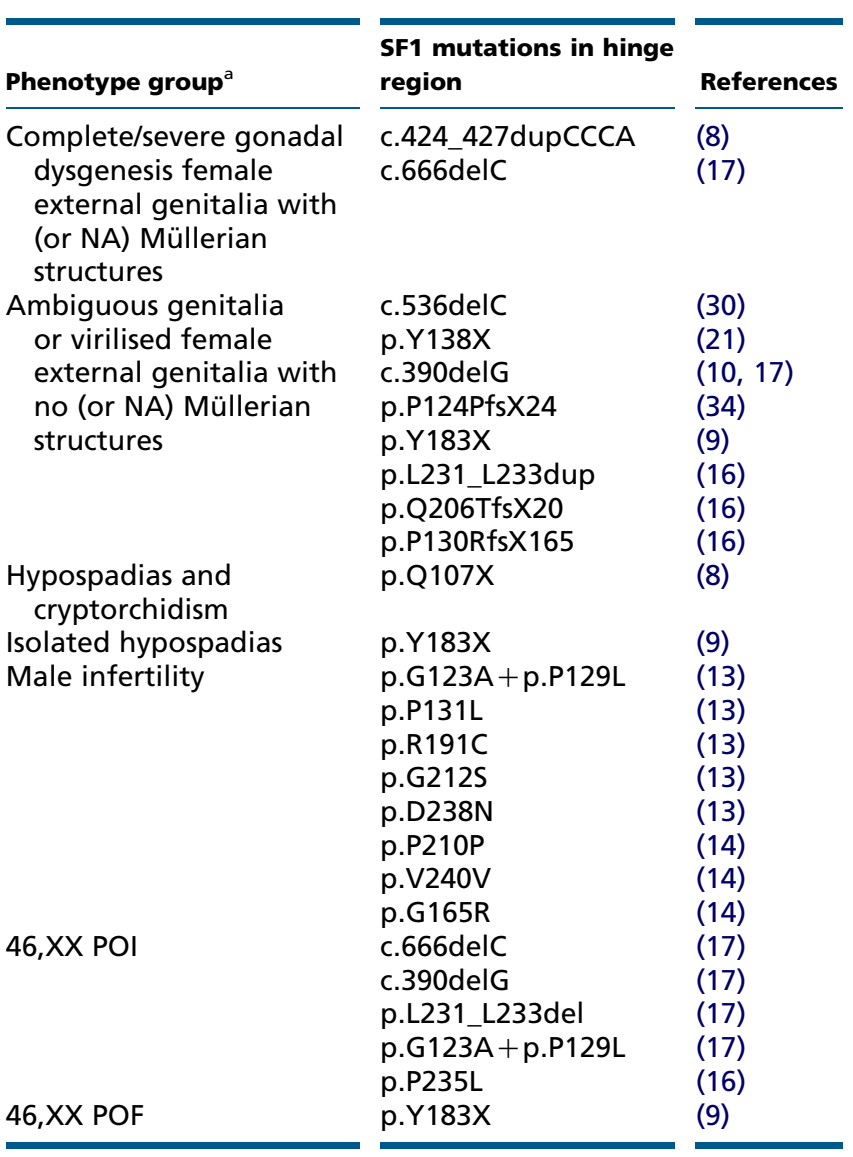

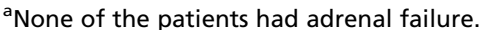

We hypothesise that the mild clinical picture of patient 3 might be attributed to the less critical mutation in the hinge region. However, so far, the p.Ala154Thr mutant did not show reduced transcriptional activity in vitro. But, interaction of the mutant with modifying factors affecting testosterone production through protein interaction might play a role in the development of hypospadias in this patient. Further studies are needed to support this hypothesis. So far, almost only nonsense mutations in the hinge region have been reported in the DSD phenotypes $(9,10,16,17,21,30,34)$, hypospadias $(8,9), 46, \mathrm{XX}$ primary ovarian insufficiency $(16,17)$ and premature ovarian failure (9). In contrast, only missense mutations in the hinge region were detected in the minor DSD phenotype of male infertility $(13,14)$ (Table 2$)$.

Interestingly, the unaffected father of patient 3 harboured the same mutation. Previously, another case was reported with a heterozygous NR5A1 mutation (p.Arg281Pro) transmitted by the unaffected father to his son with hypospadias and testicular dysgenesis (40). Mosaicism was suggested to be the reason for the different phenotypes in the father and son as the mutation was detected in the father's DNA at a low copy number through direct sequencing and high-resolution melting assay (40). In our case, the father's and son's mutations showed similar strength in the sequences (data not shown). However, genetic modifier, thresholds or dosage effects of SF1 might contribute to the different phenotypes of father and son.

The p.Gly146Ala polymorphism, which was described previously as having reduced transcriptional activity and being associated with micropenis or cryptorchidism, was found to be very frequent in our Egyptian cohort with $46, X Y$ DSD and the controls in this study. We detected the heterozygous form of this SNP (Ala/Gly genotype) in 34\% of our patients and $26 \%$ of controls. Moreover, the SNP was found in a homozygous form (Ala/Ala genotype) in $5 \%$ of controls. The high frequency of p.Gly146Ala in our controls suggests no pathogenicity compared with the previous studies $(28,29)$.

This is the first work searching for NR5A1 mutations in patients from the Middle East and Arab region with high consanguinity suggesting a high frequency of NR5A1 mutations as in European cohorts.

The type and location of the mutation might be the cause of some differences of the phenotypes. However, most probably, other additional modifying factors or digenic mutations should be considered especially in familial cases (35). 
In conclusion, we also recommend the screening of NR5A1 in patients with hypospadias and gonadal dysgenesis as well as yearly follow-ups of gonadal function beginning at puberty due to the risk of future fertility problems. As the clinical consequences are not yet clear, more outcome data are needed before recommending general screening of NR5A1 in isolated hypospadias. However, future mild progressive effects on the gonadals resulting in male infertility cannot be excluded in this case, as also infertile males with normal male phenotypes and NR5A1 mutations were described recently $(13,14)$.

\section{Declaration of interest}

The authors declare that there is no conflict of interest that could be perceived as prejudicing the impartiality of the research reported.

\section{Funding}

This study was supported by the German Egyptian Research Long-term Scholarship (GERLS) of the German Academic Exchange Service (DAAD) (S Tantawy, A1092239).

\section{References}

1 Lee PA, Houk CP, Ahmed SF \& Hughes IA. Consensus statement on management of intersex disorders. International Consensus Conference on Intersex. Pediatrics 2006118 e488-e500. (doi:10.1542/peds. 2006-0738)

2 Mazen I, El-Ruby M, Kamal R, El-Nekhely I, El-Ghandour M, Tantawy S \& El-Gammal M. Screening of genital anomalies in newborns and infants in two Egyptian governorates. Hormone Research in Paediatrics 201073 438-442. (doi:10.1159/000313588)

3 Hamerton JL, Canning N, Ray M \& Smith S. A cytogenetic survey of 14,069 newborn infants. I. Incidence of chromosome abnormalities. Clinical Genetics 19758 223-243. (doi:10.1111/j.1399-0004.1975.tb01498.x)

4 Mazen I, Hiort O, Bassiouny R \& El Gammal M. Differential diagnosis of disorders of sex development in Egypt. Hormone Research $2008 \mathbf{7 0}$ 118-123. (doi:10.1159/000137657)

5 Mazen I, Gad YZ \& Khalil A. Intersex disorders among Egyptian patients. Journal of Arab Child 19967.

6 Parker KL \& Schimmer BP. Steroidogenic factor 1: a key determinant of endocrine development and function. Endocrine Reviews 199718 361-377. (doi:10.1210/edrv.18.3.0301)

7 Luo X, Ikeda Y \& Parker KL. A cell-specific nuclear receptor is essential for adrenal and gonadal development and sexual differentiation. Cell 199477 481-490. (doi:10.1016/0092-8674(94)90211-9)

8 Kohler B, Lin L, Mazen I, Cetindag C, Biebermann H, Akkurt I, Rossi R, Hiort O, Gruters A \& Achermann JC. The spectrum of phenotypes associated with mutations in steroidogenic factor 1 (SF-1, NR5A1, Ad4BP) includes severe penoscrotal hypospadias in 46,XY males without adrenal insufficiency. European Journal of Endocrinology 2009 161 237-242. (doi:10.1530/EJE-09-0067)

9 Warman DM, Costanzo M, Marino R, Berensztein E, Galeano J, Ramirez PC, Saraco N, Baquedano MS, Ciaccio M, Guercio G et al. Three new SF-1 (NR5A1) gene mutations in two unrelated families with multiple affected members: within-family variability in 46 , XY subjects and low ovarian reserve in fertile 46,XX subjects. Hormone Research in Paediatrics 201175 70-77. (doi:10.1159/000320029)

10 Allali S, Muller JB, Brauner R, Lourenco D, Boudjenah R, Karageorgou V, Trivin C, Lottmann H, Lortat-Jacob S, Nihoul-Fekete C et al. Mutation analysis of NR5A1 encoding steroidogenic factor 1 in 77 patients with 46, XY disorders of sex development (DSD) including hypospadias. PLoS ONE 20116 e24117. (doi:10.1371/journal.pone.0024117)

11 Philibert P, Zenaty D, Lin L, Soskin S, Audran F, Leger J, Achermann JC \& Sultan C. Mutational analysis of steroidogenic factor 1 (NR5a1) in 24 boys with bilateral anorchia: a French collaborative study. Human Reproduction 200722 3255-3261. (doi:10.1093/humrep/dem278)

12 Paris F, De Ferran K, Bhangoo A, Ten S, Lahlou N, Audran F, Servant N, Poulat F, Philibert P \& Sultan C. Isolated 'idiopathic' micropenis: hidden genetic defects? International Journal of Andrology 201134 e518-e525. (doi:10.1111/j.1365-2605.2010.01135.x)

13 Bashamboo A \& McElreavey K. NR5A1/SF-1 and development and function of the ovary. Annales d'Endocrinologie 201071 177-182. (doi:10.1016/j.ando.2010.02.013)

14 Ropke A, Tewes AC, Gromoll J, Kliesch S, Wieacker P \& Tuttelmann F. Comprehensive sequence analysis of the NR5A1 gene encoding steroidogenic factor 1 in a large group of infertile males. European Journal of Human Genetics 201321 1012-1015. (doi:10.1038/ejhg. 2012.290)

15 Philibert P, Paris F, Lakhal B, Audran F, Gaspari L, Saad A, ChristinMaitre S, Bouchard P \& Sultan C. NR5A1 (SF-1) gene variants in a group of 26 young women with XX primary ovarian insufficiency. Fertility and Sterility 201299 484-489. (doi:10.1016/j.fertnstert.2012.10.026)

16 Camats N, Pandey AV, Fernandez-Cancio M, Andaluz P, Janner M, Toran N, Moreno F, Bereket A, Akcay T, Garcia-Garcia E et al. Ten novel mutations in the NR5A1 gene cause disordered sex development in $46, \mathrm{XY}$ and ovarian insufficiency in 46,XX individuals. Journal of Clinical Endocrinology and Metabolism 201297 E1294-E1306. (doi:10.1210/ jc.2011-3169)

17 Lourenco D, Brauner R, Lin L, De Perdigo A, Weryha G, Muresan M, Boudjenah R, Guerra-Junior G, Maciel-Guerra AT, Achermann JC et al. Mutations in NR5A1 associated with ovarian insufficiency. New England Journal of Medicine 2009360 1200-1210. (doi:10.1056/ NEJMoa0806228)

18 Ciaccio M, Costanzo M, Guercio G, De Dona V, Marino R, Ramirez PC, Galeano J, Warman DM, Berensztein E, Saraco N et al. Preserved fertility in a patient with a $46, \mathrm{XY}$ disorder of sex development due to a new heterozygous mutation in the NR5A1/SF-1 gene: evidence of $46, \mathrm{XY}$ and 46 , XX gonadal dysgenesis phenotype variability in multiple members of an affected kindred. Hormone Research in Paediatrics 201278 119-126. (doi:10.1159/000338346)

19 Bashamboo A, Ravel C, Brauner R \& McElreavey K. NR5A1 and ovarian failure. Médecine Sciences 200925 809-813.

20 Seabright M. A rapid banding technique for human chromosomes. Lancet 19712 971-972. (doi:10.1016/S0140-6736(71)90287-X)

21 Kohler B, Lin L, Ferraz-de-Souza B, Wieacker P, Heidemann P, Schroder V, Biebermann H, Schnabel D, Gruters A \& Achermann JC. Five novel mutations in steroidogenic factor 1 (SF1, NR5A1) in 46,XY patients with severe underandrogenization but without adrenal insufficiency. Human Mutation 200829 59-64. (doi:10.1002/humu.20588)

22 Democratic Republic of Egypt 2008: results from the Demographic and Health Survey. Studies in Family Planning 201041 153-158. (doi:10. 1111/j.1728-4465.2010.00239.x

23 Shawky RM, El-Awady MY, Elsayed SM \& Hamadan GE. Consanguineous matings among Egyptian population. Egyptian Journal of Medical Human Genetics 201112 157-163. (doi:10.1016/j.ejmhg.2011.07.001)

24 Hoivik EA, Lewis AE, Aumo L \& Bakke M. Molecular aspects of steroidogenic factor 1 (SF-1). Molecular and Cellular Endocrinology 2010 315 27-39. (doi:10.1016/j.mce.2009.07.003)

25 Andersson AM. Inhibin B in the assessment of seminiferous tubular function. Baillieres Best Practice \& Research. Clinical Endocrinology \& Metabolism 200014 389-397. 
26 Aksglaede L, Sørensen K, Boas M, Mouritsen A, Hagen CP, Jensen RB, Petersen JH, Linneberg A, Andersson AM, Main KM et al. Changes in antiMüllerian hormone (AMH) throughout the life span: a population-based study of 1027 healthy males from birth (cord blood) to the age of 69 years. Journal of Clinical Endocrinology and Metabolism 201095 5357-5364.

27 Genomes Project C, Abecasis GR, Altshuler D, Auton A, Brooks LD, Durbin RM, Gibbs RA, Hurles ME \& McVean GA. A map of human genome variation from population-scale sequencing. Nature 2010467 1061-1073. (doi:10.1038/nature09534)

28 Wada Y, Okada M, Fukami M, Sasagawa I \& Ogata T. Association of cryptorchidism with Gly146Ala polymorphism in the gene for steroidogenic factor-1. Fertility and Sterility $2006 \mathbf{8 5}$ 787-790. (doi:10.1016/j.fertnstert.2005.09.016)

29 Wada Y, Okada M, Hasegawa T \& Ogata T. Association of severe micropenis with Gly146Ala polymorphism in the gene for steroidogenic factor-1. Endocrine Journal 200552 445-448. (doi:10.1507/ endocrj.52.445)

30 Coutant R, Mallet D, Lahlou N, Bouhours-Nouet N, Guichet A, Coupris L, Croue A \& Morel Y. Heterozygous mutation of steroidogenic factor-1 in 46,XY subjects may mimic partial androgen insensitivity syndrome. Journal of Clinical Endocrinology and Metabolism 200792 2868-2873. (doi:10.1210/jc.2007-0024)

31 Lin L, Philibert P, Ferraz-de-Souza B, Kelberman D, Homfray T, Albanese A, Molini V, Sebire NJ, Einaudi S, Conway GS et al. Heterozygous missense mutations in steroidogenic factor 1 (SF1/Ad4BP, NR5A1) are associated with 46,XY disorders of sex development with normal adrenal function. Journal of Clinical Endocrinology and Metabolism 200792 991-999. (doi:10.1210/jc.2006-1672)

32 Reuter AL, Goji K, Bingham NC, Matsuo M \& Parker KL. A novel mutation in the accessory DNA-binding domain of human steroidogenic factor 1 causes XY gonadal dysgenesis without adrenal insufficiency. European Journal of Endocrinology 2007157 233-238. (doi:10.1530/EJE-07-0113)

33 Tajima T, Fujiwara F \& Fujieda K. A novel heterozygous mutation of steroidogenic factor-1 (SF-1/Ad4BP) gene (NR5A1) in a 46, XY disorders of sex development (DSD) patient without adrenal failure. Endocrine Journal 200956 619-624. (doi:10.1507/endocrj.K08E-380)

34 Philibert P, Leprieur E, Zenaty D, Thibaud E, Polak M, Frances AM, Lespinasse J, Raingeard I, Servant N, Audran F et al. Steroidogenic factor-1 (SF-1) gene mutation as a frequent cause of primary amenorrhea in 46,XY female adolescents with low testosterone concentration. Reproductive Biology and Endocrinology 2010828. (doi:10.1186/1477-7827-8-28)

35 Ferraz-de-Souza B, Lin L \& Achermann JC. Steroidogenic factor-1 (SF-1, NR5A1) and human disease. Molecular and Cellular Endocrinology 2011 336 198-205. (doi:10.1016/j.mce.2010.11.006)

36 Tantawy S, Lin L, Akkurt I, Borck G, Klingmuller D, Hauffa BP, Krude H, Biebermann H, Achermann JC \& Kohler B. Testosterone production during puberty in two 46 , XY patients with disorders of sex development and novel NR5A1 (SF-1) mutations. European Journal of Endocrinology 2012167 125-130. (doi:10.1530/EJE-11-0944)

37 Soardi FC, Coeli FB, Maciel-Guerra AT, Guerra-Junior G \& Mello MP. Complete XY gonadal dysgenesis due to p.D293N homozygous mutation in the NR5A1 gene: a case study. Journal of Applied Genetics 201051 223-224. (doi:10.1007/BF03195733)

38 Achermann JC, Ito M, Ito M, Hindmarsh PC \& Jameson JL. A mutation in the gene encoding steroidogenic factor- 1 causes XY sex reversal and adrenal failure in humans. Nature Genetics 199922 125-126. (doi:10.1038/9629)

39 Achermann JC, Ozisik G, Ito M, Orun UA, Harmanci K, Gurakan B \& Jameson JL. Gonadal determination and adrenal development are regulated by the orphan nuclear receptor steroidogenic factor- 1 , in a dose-dependent manner. Journal of Clinical Endocrinology and Metabolism 200287 1829-1833. (doi:10.1210/jcem.87.4.8376)

40 Philibert P, Polak M, Colmenares A, Lortat-Jacob S, Audran F, Poulat F \& Sultan C. Predominant Sertoli cell deficiency in a $46, \mathrm{XY}$ disorders of sex development patient with a new NR5A1/SF-1 mutation transmitted by his unaffected father. Fertility and Sterility $2011 \mathbf{1 7 8 8}$ e1785-e1789.

Received 27 November 2013

Revised version received 18 February 2014

Accepted 3 March 2014 